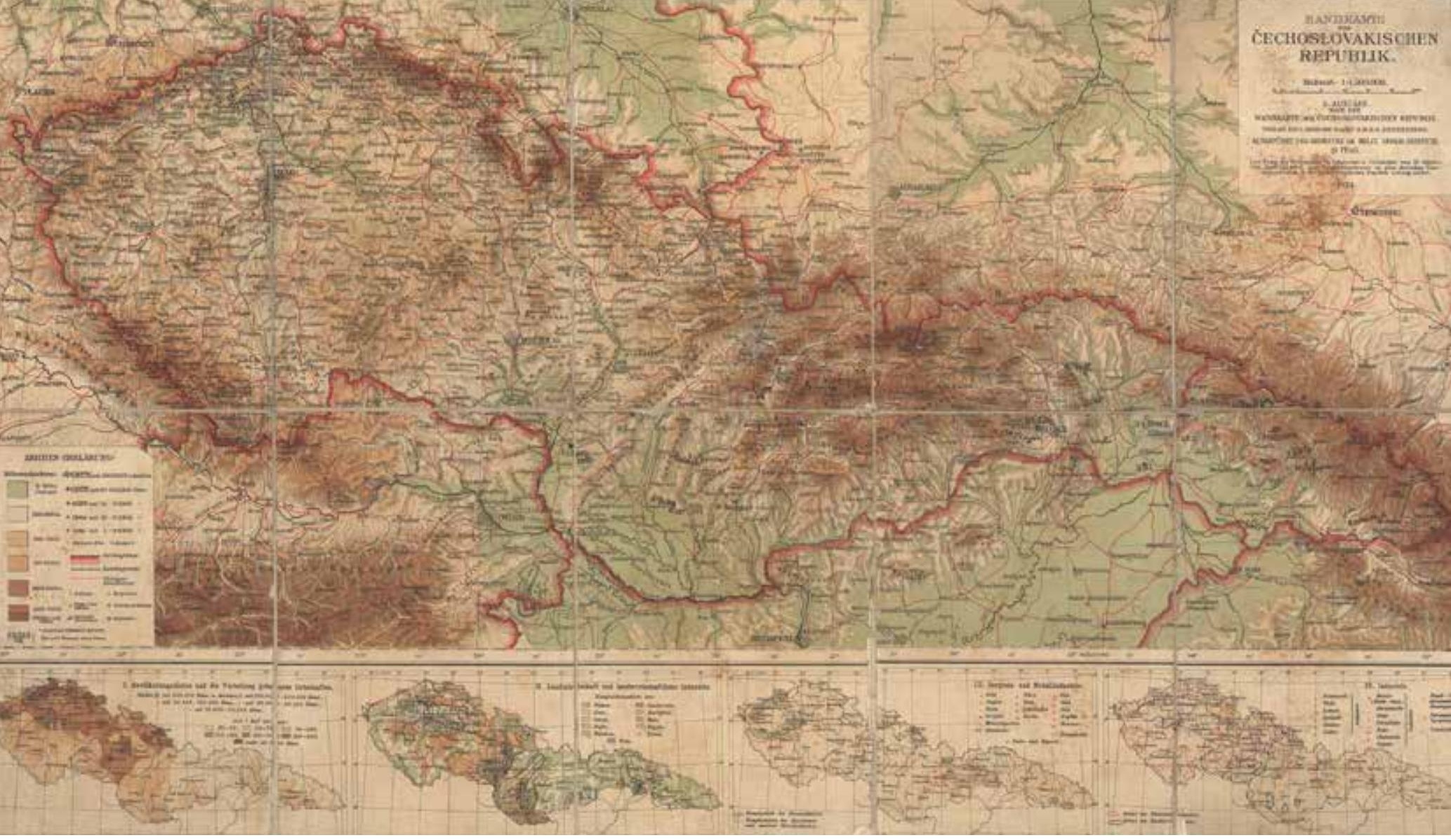

\title{
Deutsche und Tschechen in der ersten Tschechoslowakischen Republik und im Reichsgau Sudetenland 1918 bis 1945
}

\author{
Lars-Arne Dannenberg, Matthias Donath
}

Handkarte der čechoslovakischen Republik, 1924.

Die Tschechoslowakische Republik war ein Zentralstaat. Sie setzte sich aus verschiedenen Landesteilen zusammen (Böhmen, Mähren, Schlesien, Slowakei, Karpatenrussland), war aber nicht föderal organisiert. Die Landkarte war für den Gebrauch in Schulen zugelassen. Orte mit tschechischer Mehrheit sind ausschließlich mit ihrem tschechischen Namen, Orte mit deutscher Mehrheit mit ihrem deutschen Namen bezeichnet.

- Bayerisches Hauptstaatsarchiv München, Sudetendeutsches Archiv
Deutsche und Tschechen im Königreich Böhmen

Das bis 1918 bestehende Königreich Böhmen war ein Land mit zwei Völkern und zwei Sprachen. Nach der Volkszählung von 1910 waren 62,7 Prozent, fast zwei Drittel der Einwohner, Tschechen, die sich im Alltag der tschechischen Sprache bedienten. 37,3 Prozent der Einwohner betrachteten sich als Deutsche. Ihre Vorfahren waren im 13. Jahrhundert von den böhmischen Königen ins Land geholt worden, wo sie brachliegendes Land besiedelten und Städte gründeten. Im Lauf der Jahrhunderte hatte sich eine gegenseitige Assimilation vollzogen, was zu einer Ausbildung geschlossener Sprachgebiete führte. In Nordböhmen, im nördlichen Teil Westböhmens sowie in den Randregionen Südböhmens herrschte die deutsche Sprache vor. In den übrigen Landesteilen dominierte die tschechische Sprache. Jedoch gab es im mehrheitlich tschechischen Gebiet auch deutsche „Sprachinseln“ beziehungsweise deutsche Minderheiten, etwa in Budweis (České Budějovice) und Prag. Die Sprachgrenze zwischen Deutsch und Tschechisch hatte sich seit dem 16. Jahrhundert verfestigt. Sie änderte sich im 19. Jahrhundert nur geringfügig, etwa durch Zuwanderung der ländlichen Bevölkerung tschechischer Sprache in die Städte und in die Industriegebiete Nordböhmens.

Die Deutschen in Böhmen betrachteten sich nicht als Minderheit, denn sie lebten vorwiegend in Gebieten, wo sie selbst in der Mehrheit waren. Außerdem war im österreichischen Teil der Habsburger-Monarchie, zu dem Böhmen 
gehörte, Deutsch die vorherrschende Amtssprache. Von den Deutschen im Deutschen Reich unterschied man sich durch zahlreiche kulturelle wie konfessionelle Eigenheiten. Die Einwohner Böhmens waren Staatsbürger der österreichisch-ungarischen Monarchie. Am Erzgebirgskamm traf dieser Vielvölkerstaat auf das 1871 unter preußischer Vorherrschaft gebildete Deutsche Reich. Hier bestand zwar keine Sprachgrenze, dafür eine Staats-, Konfessions-, Währungs- und Wirtschaftsgrenze. Die Deutschen Böhmens blickten nach Prag und Wien, nicht nach Berlin.

Abgesehen von der Sprache waren die Unterschiede im Alltagsleben der deutschen und tschechischen Bevölkerung eher gering. Die Einwohner Böhmens waren seit Durchsetzung der Gegenreformation fast ausschließlich römisch-katholischen Glaubens. 1905 bekannten sich 96 Prozent zum Katholizismus. Die katholische Frömmigkeit bestimmte den Alltag vieler Menschen. Auch bei der Küche waren die Unterschiede marginal. Tschechen wie Deutsche hatten ähnliche Ess- und Trinkgewohnheiten und verspeisten die gleichen Gerichte. Für das alltägliche Leben war über Jahrhunderte nicht die Sprache von Bedeutung, sondern die soziale Stellung innerhalb der ständisch gegliederten Gesellschaft.

Das Bewusstsein für eine Verschiedenheit der deutsch- und tschechischsprachigen Bevölkerungsteile Böhmens und Mährens setzte erst im 19. Jahrhundert ein, als im „nationalen Zeitalter" die Idee ethnisch definierter Nationen propagiert wurde, die in eigenen Nationalstaaten leben. So bildete sich eine tschechische Nationalbewegung heraus. Wissenschaftliche Vereine sowie Kultur- und Sportverbände setzten sich für die Anerkennung und Verwendung der tschechischen Sprache ein. Dem folgte das Verlangen nach politischer Selbstbestimmung. Die „nationale Wiedergeburt“ stärkte das Selbstbewusstsein der tschechischen Mehrheit. Diese identifizierte sich ganz selbstverständlich mit dem gesamten Land, denn in der tschechischen Sprache wird nicht zwischen „tschechisch“ und „böhmisch“ unterschieden. Dagegen werden in der deutschen Sprache für das Land und für das slawische Volk verschiedene Begriffe gebraucht. Die deutschen Landesbewohner betrachteten sich als Deutschböhmen. Der Begriff „Sudetendeutsche“ ist vergleichsweise spät entstanden. Der Prager Geograf Franz Jesser (1869-1954) prägte ihn 1902 für die deutschsprachige Bevölkerung Böhmens und Mährens. Er leitet sich vom Gebirgszug der Sudeten ab, der aber nur einen kleinen Teil des deutschen Sprachgebiets in Böhmen berührt. Vor 1918 war er kaum in
Gebrauch. Die Bezeichnung setzte sich erst nach der Gründung der Tschechoslowakei durch, weil die Behörden des jungen Staates die Verwendung der Begriffe „Deutschböhmen“ und „Deutschmährer“ untersagten.

Böhmen war das wirtschaftlich stärkste Kronland der österreichischen Monarchie. Im vr 19. Jahrhundert hatte sich ein immenser wirtschaftlicher Aufschwung vollzogen. Die Industrie war aber ungleich verteilt. Vor allem in den deutschsprachigen Randgebieten Nordböhmens waren bedeutende Industriebetriebe entstanden. Bestimmende Wirtschaftszweige waren die Textilindustrie, der Bergbau, die Gebrauchsgüterindustrie und - im Isergebirge - die Glas- und Schmuckherstellung. Wirtschaft, Verkehr und Handel waren im ganzen Land miteinander vernetzt und machten nicht an den Sprachgrenzen halt. Obwohl die Industrialisierung auch die Städte in den Randgebieten Böhmens hatten wachsen lassen, blieb die Hauptstadt Prag die prägende Metropole des Landes. Auch die Deutschböhmen blickten nach Prag, wo sich die wichtigsten Einrichtungen des Landes befanden.

\section{Der Zusammenbruch Österreich-Ungarns und die Gründung der Tschechoslowaki- schen Republik}

Die tschechische Nationalbewegung ging von einem „historischen und natürlichen Recht“ der Tschechen an Böhmen und Mähren aus und forderte ein engeres Zusammenwirken der slawischen Völker in Österreich-Ungarn. Diese Bestrebungen richteten sich zunächst noch nicht gegen die Herrschaft der Habsburger. So verlangten die Jungtschechen - Ende des 19. Jahrhunderts die dominierende tschechische Partei - zwar einen autonomen tschechischen Staat, doch sollte dieser innerhalb der Habsburger-Monarchie gebildet werden. Im Ersten Weltkrieg kämpften deutsche und tschechische Soldaten gemeinsam in der Armee Österreich-Ungarns gegen die Kriegsgegner Serbien, Russland und Italien. Mit der Fortdauer des Krieges wuchs allerdings die Unzufriedenheit der tschechischen Bevölkerung.

Währenddessen dachten tschechische und slowakische Intellektuelle, die in den USA lebten beziehungsweise nach Kriegsbeginn auf die Seite der Alliierten getreten waren, über eine neue Staatsidee nach. Im Hinblick auf die Verwandtschaft der tschechischen und slowakischen Sprache entwickelten sie den Gedanken, aus den Ländern der böhmischen Krone und dem slowakischen Siedlungsgebiet des Königreichs Ungarn einen neuen Nationalstaat der Tschechen und Slowaken zu bilden. Die Slowaken befürchteten, 
Postkarte „3 $1 \frac{1}{2}$ Millionen Deutsche wollen frei sein!" mit Eintragung des deutschen Siedlungsgebiets in den böhmischen Ländern, 1919. Mit Postkarten wie dieser warben die politischen Vertreter der Provinzen Deutschböhmen und Sudetenland um internationale Anerkennung ihres Selbstbestimmungsrechts. Die Postkarten wurden in

hoher Auflage gedruckt und in verschiedenen europäischen Staaten verteilt. ๑) Sammlung ZKG

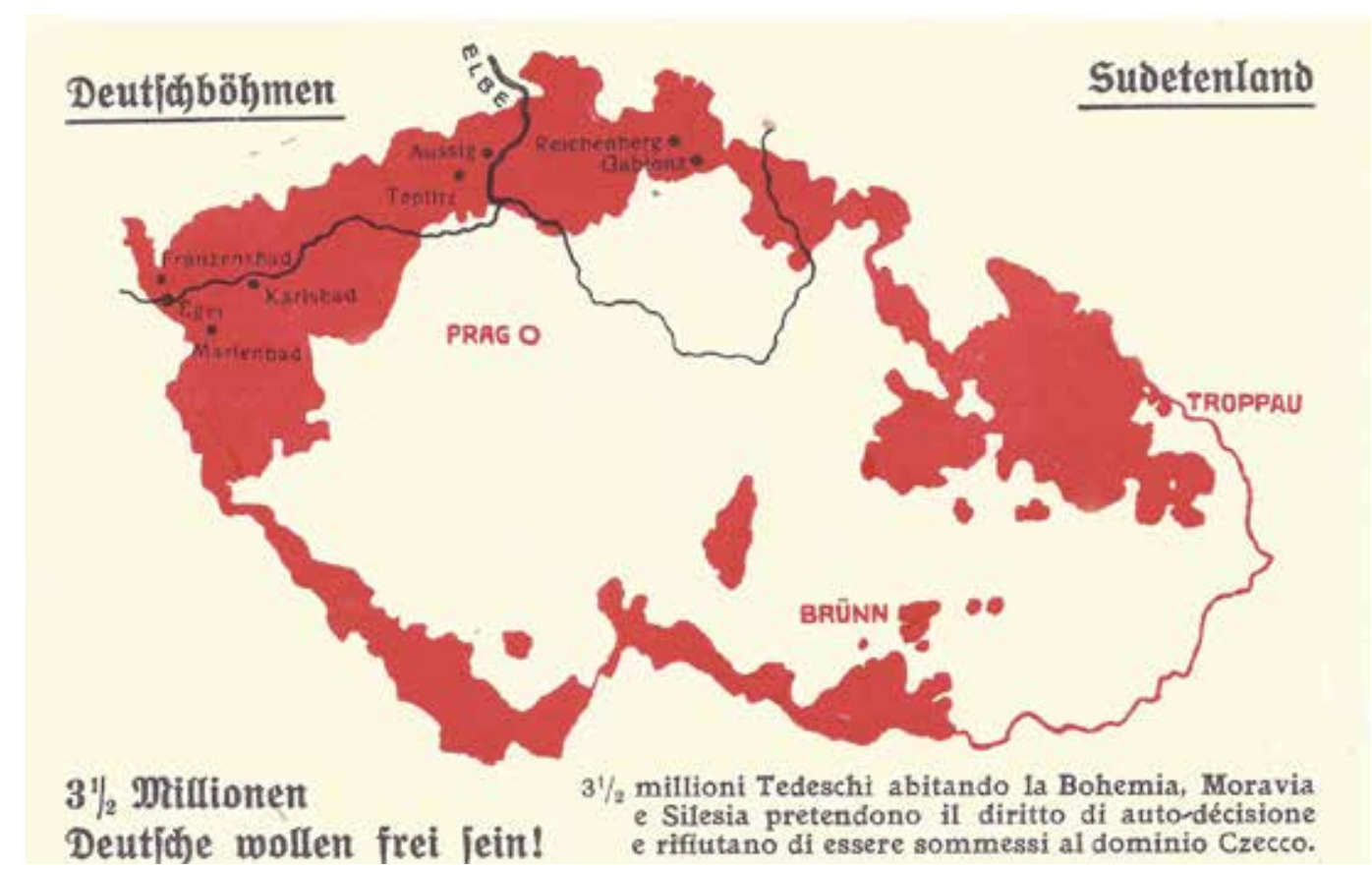

sich ohne die Hilfe der Tschechen nicht aus dem ungarischen Staatsverband lösen zu können, während die Tschechen eine slawische Mehrheit im neuen Staat sicherstellen wollten. Der in Mähren geborene Tomáš Garrigue Masaryk (1850-1937) und sein Mitarbeiter Edvard Beneš (1884-1948) waren die prägenden Vertreter dieser Staatsidee. 1917 stellten sie aus tschechischen Soldaten, die in Gefangenschaft geraten oder zu den Alliierten übergelaufen waren, die Tschechoslowakische Legion auf, die auf Seiten Frankreichs und Russlands gegen das Deutsche Reich und Österreich-Ungarn kämpfte. Als der amerikanische Präsident Woodrow Wilson (1856-1924) am 8. Januar 1918 in seinem 14-Punkte-Programm den Völkern ÖsterreichUngarns die „freieste Gelegenheit zu autonomer Entwicklung“ zusprach, war damit noch nicht eine Zerschlagung des Vielvölkerstaats gemeint. Es gelang jedoch Masaryk im Verlauf des Jahres 1918, die Alliierten von einer tschechoslowakischen Staatsbildung zu überzeugen.

Tschechische und slowakische Exilgruppen schlossen am 31. Mai 1918 den Pittsburgher Vertrag, der die Gründung einer demokratischen Republik mit gleichberechtigter Beteiligung der Tschechen und Slowaken vorsah, und bildeten einen Tschechoslowakischen Nationalausschuss. Das weitere Geschehen wurde dadurch beeinflusst, dass sich im Herbst 1918 die militärische Niederlage der Mittelmächte abzeichnete. Kaiser Karl I. (1887 -1922) versuchte wenigstens die österreichische Reichshälfte zu retten, indem er am 16. Oktober 1918 die Umwandlung in einen Bundesstaat mit weitgehender Autonomie für die einzelnen Nationen versprach. Doch das war zu spät.
Zwei Tage später proklamierte Masaryk in Washington den unabhängigen tschechoslowakischen Staat. Ende Oktober löste sich die Armee Österreich-Ungarns auf und die Befehlshaber Unter diesen Umständen wurde am 28. Oktober 1918 in Prag die Tschechoslowakische Republik ausgerufen. Der Tschechoslowakische Nationalausschuss beschloss das erste Gesetz, betreffend die Errichtung des selbständigen tschechoslowakischen Staates. Am 14. November 1918 wurde Masaryk von der Tschechoslowakischen Nationalversammlung zum Präsidenten gewählt, und am 21. Dezember 1918 kehrte er aus dem Exil in sein Heimatland zurück.

Die deutschen Bevölkerungsteile Österreich-Ungarns reagierten ebenfalls auf den Zerfall der Habsburger-Monarchie, aber sie waren anders als die nichtdeutschen Völker nicht auf eine Staatsgründung vorbereitet. Die deutschsprachigen Abgeordneten des letzten Reichsrats bildeten am 21. Oktober 1918 in Wien eine provisorische Nationalversammlung. Diese beschloss nach der Abdankung des Kaisers die Errichtung der Republik Deutschösterreich. Diesem Staat, der sich als Teil einer deutschen Republik betrachtete, schlossen sich auch mehrere deutsch besiedelte Gebiete Böhmens an, die sich am 29. Oktober 1918, ein Tag nach Gründung der Tschechoslowakei, als Republiken konstituierten. Das war zum einen die Republik Deutschböhmen mit Regierungssitz in Reichenberg (Liberec), die die westlichen und nördlichen Randgebiete Böhmens umfassen sollte, und zum anderen die Republik Sudetenland, zu der ein Teil Nordostböhmens, die mehrheitlich deutsch besiedelten Teilen Nordmährens und mussten in einen Waffenstillstand einwilligen. 
Österreichisch-Schlesien gehören sollten. In Reichenberg nahm eine deutschböhmische Landesregierung unter dem Landeshauptmann Rudolf Lodgman von Auen (1877-1962) ihre Arbeit auf. Am 16. November 1918 erklärten sich die Republiken zu Provinzen der Republik Deutschösterreich. Auch Deutschsüdmähren und der Böhmerwaldgau wollten sich Deutschösterreich anschließen.

Der von der deutschen Seite betriebenen Teilung Böhmens stand der Anspruch des Tschechoslowakischen Nationalausschusses auf sämtliche Gebiete Böhmens und Mähren gegenüber, was mit dem „Naturrecht“ begründet wurde. Somit trafen hier zwei widerstrebende Nationalbewegungen zusammen: Auf der einen Seite stand das Selbstbestimmungsrecht der tschechischen Nation, auf der anderen Seite der Wunsch der deutschen Volksgruppen Österreich-Ungarns, ihre Angelegenheiten ebenfalls selbst zu bestimmten. Die Siegermächte des Ersten Weltkriegs missachteten dieses deutsche Selbstbestimmungsrecht, weil sie kein Interesse an einem großdeutschen Nationalstaat in Mitteleuropa hatten, der den Kriegsgegner, das Deutsche Reich, gestärkt hätte.

Mit Zustimmung der Alliierten besetzten tschechische Militäreinheiten im November und Dezember 1918 die deutsch besiedelten Landesteile, die vollständig in den neuen Staat integriert wurden. Die deutschböhmische Landesregierung floh aus Reichenberg über Dresden nach Wien, wo Rudolf Lodgman von Auen weiterhin für einen deutschen Staat in Böhmen warb. Bei den Friedensverhandlungen in SaintGermain bei Paris konnte sich die tschechische Seite jedoch vollständig durchsetzen. Die Siegermächte sprachen der Tschechoslowakei Böhmen, Mähren, Österreichisch-Schlesien und einige Gemeinden Niederösterreichs zu, während das Selbstbestimmungsrecht der deutschen Bevölkerungsteile unberücksichtigt blieb. Am 24. September 1919 schließlich erkannte die Republik Österreich - der Staatsname „Deutschösterreich“ und der Anschluss an das Deutsche Reich waren in Saint-Germain verboten worden - die Abtretung der deutschen Gebiete Böhmens an die Tschechoslowakei an.

Die Besetzung der deutsch besiedelten Gebiete durch tschechoslowakische Truppen vollzog sich unter dem Protest der einheimischen Bevölkerung und der deutschböhmischen Parteien verschiedener politischer Richtungen, die sich infolge der Revolution 1918/19 gebildet hatten. So demonstrierten am 4. März 1919, als die Nationalversammlung Deutschösterreichs in Wien eröffnet wurde, tausende Menschen in allen größeren Städten gegen die Vorenthaltung des Selbstbestimmungsrechts. An mehreren Orten schossen tschechische Soldaten in die
Menschenansammlungen, so dass insgesamt 53 Demonstranten starben. In Kaaden (Kadaň) waren 25 und in Mährisch Sternberg (Šternberk) 16 Todesopfer zu beklagen. Nach diesem gewaltsamen Eingreifen war der Widerstand in den deutschsprachigen Landesteilen weitgehend erloschen.

\section{Nationalstaat oder Nationalitätenstaat?}

Die Tschechoslowakische Republik war als Nationalstaat der „Tschechoslowaken“ organisiert, obwohl es ein solches Staatsvolk tatsächlich nicht gab. Aber nur durch die zahlenmäßige Zusammenfassung der Tschechen und der Slowaken $\mathrm{zu}$ einer gemeinsamen Nation war eine deutliche slawische Mehrheit gewährleistet. Tatsächlich war die Tschechoslowakei ein ethnisch gemischter Vielvölkerstaat. Die dominierende Nation waren die Tschechen, die im neuen Staat nur etwas mehr als die Hälfte der Einwohner stellten (50,7 Prozent). In keinem anderen Staat Europas war der Bevölkerungsanteil der vorherrschenden Nation so niedrig. An zweiter Stelle folgten die Deutschen (23,4 Prozent), die sich aus den „Sudetendeutschen“ in Böhmen, Mähren und Schlesien und den „Karpatendeutschen“ in der Slowakei zusammensetzten. An dritter Stelle rangierten die Slowaken (14,7 Prozent). Sie waren zwar formell Teil der Staatsnation, doch faktisch blieb ihnen die Selbstbestimmung versagt. Die im Pittsburgher Abkommen zugesagte Autonomie der Slowakei wurde nicht verwirklicht. Weiterhin lebten in der Tschechoslowakei Ungarn (5,6 Prozent), Ukrainer (3,4 Prozent), Polen, Russinen, Russen, Rumänen, Kroaten sowie Juden, die als eigenständige Nation geführt wurden. Am schlechtesten waren die Bewohner Karpatenrusslands gestellt. Die Siegermächte des Ersten Weltkrieg hatten diese mehrheitlich von Ruthenen (Russinen und Ukrainern) bewohnte Region, die bis 1918 ein Teil des Königreichs Ungarn gewesen war, im Vertrag von Trianon der Tschechoslowakei zugesprochen, obwohl in dem Gebiet nur rund fünf Prozent Slowaken lebten. Die Ruthenen waren trotz ihrer slawischen Herkunft nicht Teil der Staatsnation der „Tschechoslowaken“.

Tomáš Garrigue Masaryk hatte 1919 in SaintGermain versprochen, einen Staat ,identisch mit dem der Schweiz“ zu schaffen, in dem Deutsch als zweite Landessprache anerkannt werde. Die deutschen Parteien waren enttäuscht, dass die Tschechoslowakische Verfassung von 1920 diese Zusagen negierte. Sie strebten die Gewährung einer Autonomie für den deutschen Bevölkerungsteil und die stufenweise Umwandlung der Tsche- 
Zweisprachiges Behördenschild mit dem Wappen der Tschechoslowakei Foto: Matthias Donath

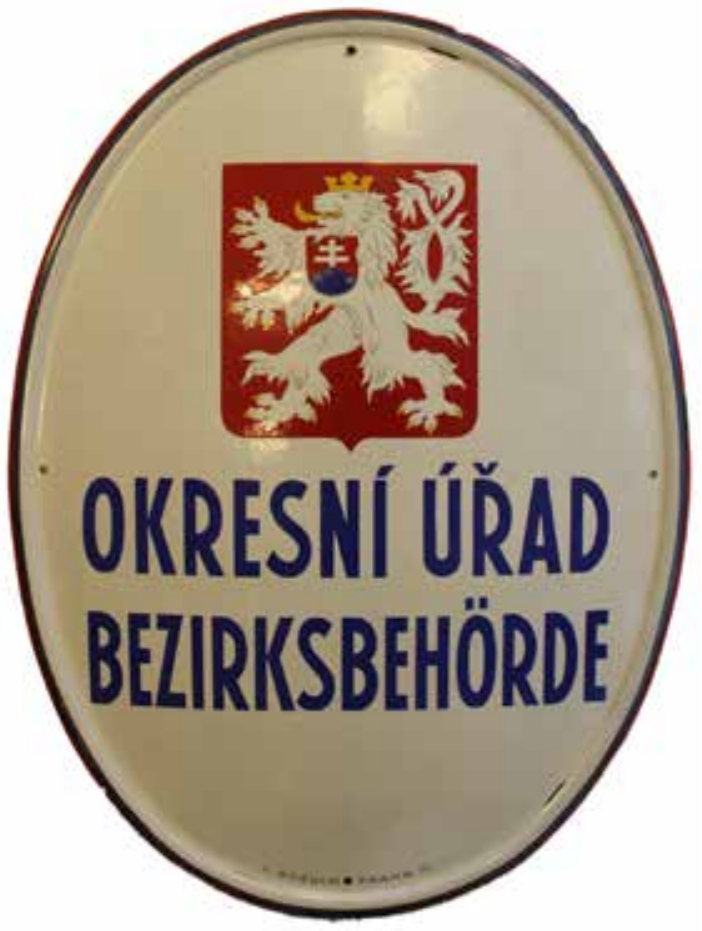

choslowakei in einen Nationalitätenstaat mehrerer gleichberechtigter Nationen an. Auch auf tschechischer Seite gab es Befürworter einer solchen „Verschweizerung“.

Die Situation der deutschen Minderheit in der Tschechoslowakei lässt sich ganz verschieden beschreiben. Zum einen war die Tschechoslowakische Republik ein demokratischer Rechtsstaat, dem die Einwohner deutscher Sprache als gleichberechtigte Staatsbürger angehörten. Im deutschen Sprachgebiet gab es deutsche Schulen, im Alltag konnten viele Angelegenheiten erledigt werden, ohne dass man sich der tschechischen Sprache bedienen musste. Orte, Straßennamen und staatliche Einrichtungen waren im deutschsprachigen Gebiet tschechisch und deutsch beschriftet. Es gab deutsche Zeitungen, deutsche Theater und ein eigenständiges deutsches Vereinsleben. In den anderen Staaten, die nach dem Ersten Weltkrieg neu entstanden waren, ging es den deutschen Minderheiten schlechter.

Zum anderen fühlten sich viele der deutschen Staatsbürger aber benachteiligt. Staatssprache in der ersten Republik war nach dem Gesetz vom 29. Februar 1920 allein „Tschechoslowakisch“ - eine Sprache, die es gar nicht gab. Beamte mussten zwingend die tschechische Sprache beherrschen und dies mit einer Sprachprüfung nachweisen. Das bedeutete, dass zahlreiche deutsche Beamte entlassen und durch tschechische ersetzt wurden. Tschechische Beamte, die in die deutschsprachigen Gebiete zogen, mussten jedoch keine Deutschkenntnisse vorweisen. In den rund zwanzig Jahren bis 1938 zogen rund 260.000 Tschechen in die mehrheit- lich deutsch besiedelten Gebiete. Dort formierte sich eine neue „Elite“ aus zugezogenen tschechischen Beamten und Offizieren, die in den Behörden, an der Grenze, im Militär oder bei der Eisenbahn ihren Dienst verrichteten. Für ihre Kinder wurden neue tschechische Volksschulen errichtet, während in sprachlich gemischten Orten, wo die Zahl deutscher Kinder gesunken war, deutsche Volksschulen schließen mussten. Bei einer umfassenden Bodenreform mussten die größtenteils adligen Großgrundbesitzer erhebliche Teile ihrer Ländereien an den Staat abgeben. Dieses Land wurde teils verstaatlicht, teils an Siedler verteilt, die aber zu 92 Prozent tschechischer Sprache waren. Diese Benachteiligungen waren bewusste Maßnahmen, weil Staatspräsident Masaryk und die Regierungsparteien eine „Entösterreichisierung“ des gesamten Landes und eine „Tschechisierung“ der deutschsprachigen Gebiete erreichen wollten. So entstand bei vielen Staatsbürgern deutscher Sprache der Eindruck „Bürger zweiter Klasse“ zu sein.

\section{Zustimmung und Ablehnung}

Die Deutschen mussten sich in dem neuen Staat zurechtfinden, den sie nicht gewollt hatten, aber in dem und mit dem sie leben mussten. Schon allein aus pragmatischen Gründen passten sie sich den Regeln des neuen Staates an. Vor allem Schule und Militärdienst trugen zu einer Integration in den tschechoslowakischen Staat bei.

Im deutschen Schulunterricht vermittelten deutsche Lehrer die tschechoslowakische Staatsidee und die Geschichte Böhmens. Die Kinder wurden so erzogen, dass sie den Staat, in dem sie lebten, und seine Symbole zu achten hatten. Tschechisch wurde als Fremdsprache unterrichtet, genauso, wie viele tschechische Schüler in der Schule Deutsch lernten. Es war weithin üblich, dass tschechische Eltern ihre Kinder für mehrere Monate in eine deutschsprachige Familie gaben und umgekehrt, dass deutsche Kinder in tschechischen Familien die Staatssprache lernten. Dieser Schüleraustausch wurde im Tschechischen als „vexl“ (Wechsel) bezeichnet. Die Deutschen mussten, wie alle anderen Staatsbürger auch, ihren Wehrdienst bei der Tschechoslowakischen Armee ableisten. Dort war Tschechisch die Dienstsprache. Wer Unteroffizier oder Offizier werden wollte, musste perfekt Tschechisch sprechen. Da die Armee ein sicheres Einkommen versprach, entschieden sich auch viele Deutsche für eine Offizierslaufbahn. Allerdings wurden die deutschen Rekruten nur selten in ihrer Heimat eingesetzt. Da man sich ihrer Loyalität nie ganz sicher war, setzte man sie nicht bei der Grenzsicherung ein. Offiziere und Mann- 
schaften deutscher Nationalität dienten vor allem in der Slowakei und in Karpatenrussland. Die erste tschechoslowakische Republik war ein pluralistischer und demokratischer Parteienstaat. Das Parteiensystem war strikt nach Sprachen getrennt. Die einzige Partei, die sich nicht danach richtete, war die Kommunistische Partei in der Tschechoslowakei. Ihr gehörten gleichermaßen tschechische und deutsche Kommunisten an. Die Arbeiterbewegung, die im stark industrialisierten Nordböhmen viele Anhänger hatte, war indes gespalten. Die größte Partei der deutschen Minderheit war lange die Deutsche sozialdemokratische Arbeiterpartei in der Tschechoslowakischen Republik (DSAP). Um den Sozialismus durchzusetzen, den sie erstrebte, entschied sie sich bald nach dem gescheiterten Anschluss an die Republik Deutschösterreich zur Mitarbeit im politischen System der Tschechoslowakei. Bei den Wahlen 1929 erzielte sie 6,9 Prozent, womit sie die stärkste deutsche Fraktion im Prager Abgeordnetenhaus stellte. Die Deutsche sozialdemokratische Arbeiterpartei gehörte zu den „aktivistischen Parteien“, die durch eine aktive Beteiligung am politischen Handeln und an der Regierung die Lebensverhältnisse ihrer deutschen Wähler zu verbessern versuchte. Obwohl anderer politischer Überzeugung, wirkte auch die Deutsche Christlich-Soziale Volkspartei (DCV) im neuen Staat mit. Sie hatte eine bürgerlich-christliche Ausrichtung. Die führende Persönlichkeit der Christsozialen war der Prager Jurist Robert Ritter von Mayr-Harting (nach der Abschaffung der Adelstitel nur MayrHarting, 1874-1948). Er sprach sich bereits unmittelbar nach dem Zusammenbruch der Monarchie für eine aktive Mitwirkung der deutschsprachigen Bevölkerung im neuen Staat aus und stand stets loyal zur Tschechoslowakei. Die deutschen Klein- und Mittelbauern wurden vom Bund der Landwirte (BdL) vertreten, einer antisozialistischen Partei, die mit der Tschechischen Agrarpartei viele Überzeugungen teilte. 1926 bildete Ministerpräsident Antonín Švehla (1873-1933) eine neue Regierung, in die er erstmals auch Vertreter deutscher Parteien aufnahm. Mayr-Harting wurde Justizminister und der Prager Slawist Franz Spina (1868-1938) vom Bund der Landwirte Minister für öffentliche Arbeiten. Als 1929 eine neue Koalitionsregierung unter Beteiligung deutscher Parteien gebildet wurde, erhielt Ludwig Czech (1870-1942), der Vorsitzende der Deutschen sozialdemokratischen Arbeiterpartei, einen Ministerposten. Er gehörte bis 1938 der Regierung an, ebenso wie Franz Spina und der 1936 zum Minister ohne Portefeuille berufene Erwin Zajicek (1890-1976) von der Deutschen Christlich-Sozialen Volkspartei.

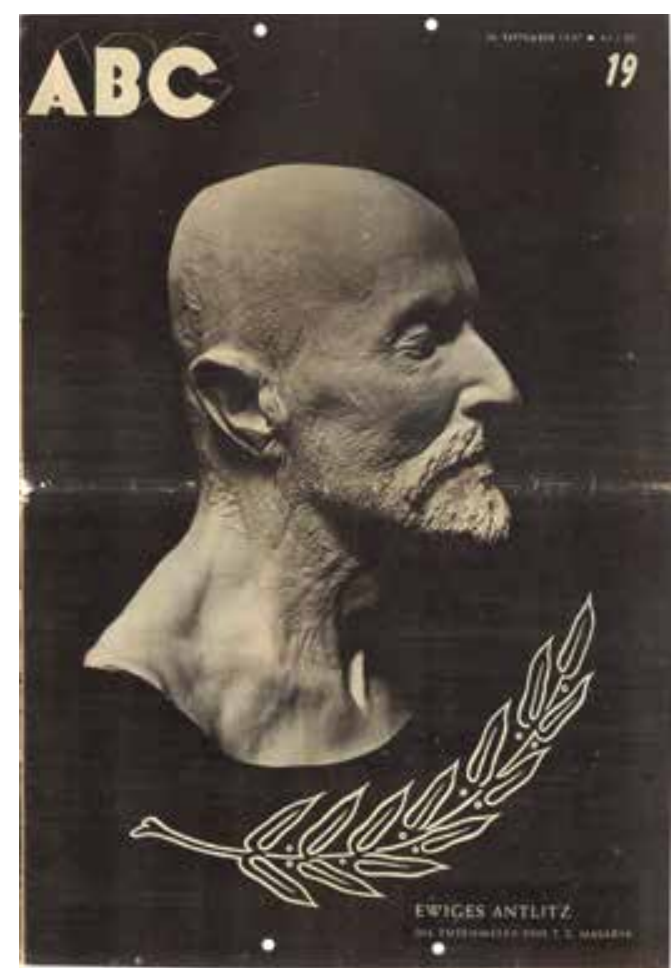

Titelseite der deutschen Zeitschrift "ABC" vom 26. September 1937 Die Deutschen, die loyal zur Tschechoslowakei standen, verehrten den Staatsgründer und ersten Präsidenten Tomáš Garrigue Masaryk. 1937 trauerte man auch in den deutschsprachigen Landesteilen um seinen Tod.

๑ Bayerisches Hauptstaatsarchiv München, Sudetendeutsches Archiv
Den „aktivistischen Parteien“ standen die „negativistischen Parteien“ gegenüber, die die Tschechoslowakei grundsätzlich ablehnten und eine Mitwirkung in der Regierung verweigerten. Rudolf Lodgman von Auen, der nach seinem Rücktritt als Landeshauptmann der Provinz Deutschböhmen in die Tschechoslowakei zurückgekehrt war, führte die Deutsche Nationalpartei (DNP), die jede Mitarbeit im politischen System der Tschechoslowakei verweigerte und eine Autonomie oder Herauslösung der deutschsprachigen Gebiete anstrebte. Bei den Wahlen von 1920 erreichte die DNP 5,3 Prozent der Stimmen, womit sie etwa ein Viertel der deutschen Wähler vertrat. Noch radikaler war die Deutsche Nationalsozialistische Arbeiterpartei (DNSAP). Dabei handelte es sich um eine völkische, antikapitalistische und antidemokratische Partei, die aus der deutschnationalen Gewerkschaftsbewegung Österreichs hervorgegangen war. Trotz des ähnlichen Namens und vergleichbarer Überzeugungen hatte sie nichts mit Adolf Hitlers Nationalsozialistischer Deutscher Arbeiterpartei (NSDAP) zu tun. 1933 lösten sich die beiden nationalistischen Parteien selbst auf, womit sie einem Parteiverbot zuvorkamen.

In Wirtschaft und Industrie konnte man sich schnell mit dem neuen Staat abfinden. Anders als im Deutschen Reich und in Österreich kam es in der Tschechoslowakei nicht zu einer Inflation und damit auch nicht zu einer Wirtschaftskrise. Die Tschechoslowakische Krone gehörte in der Zwischenkriegszeit zu den starken Währungen Europas. Die Absatzmärkte, die vor dem Krieg 
im Ausland bestanden hatten, blieben größtenteils erhalten. Der Markennamen „Made in Czechoslovakia“ hatte einen guten Ruf. Auch die Unternehmen im deutschsprachigen Gebiet nutzten diese anerkannte Marke. Um sich dem tschechischen Markt anzupassen, wurden Produkte in tschechischer Sprache beworben. Verpackungen waren oftmals zweisprachig beschriftet.

\section{Radikalisierung, die Sudetenkrise und das Ende der ersten Republik}

Die Weltwirtschaftskrise ab 1929 hatte erhebliche Auswirkungen auf die Wirtschaft in der Tschechoslowakei. Vor allem die im deutschsprachigen Gebiet konzentrierte Textil- und Schmuckindustrie war betroffen, weil Kunden und Absatzmärkte im Ausland wegfielen. Zahlreiche Betriebe mussten schließen; die Arbeitslosigkeit stieg immens an. Da es in der ersten Republik keine Arbeitslosenversicherung gab, standen viele Familien nahezu mittellos da. Die soziale Krise wirkte sich wiederum auf die politische Lage aus.

Die Unzufriedenheit wuchs außerdem, weil sich die Lage der deutschen Minderheit trotz des Regierungseintritts deutscher Parteien nicht verbesserte. Nach wie vor bestanden Benachteiligungen für Staatsbürger nichttschechischer Sprache. Von Seiten der tschechischen Parteien erfolgten keine Schritte hin zu einem Umbau des Staates hin zu einer „zweiten Schweiz“ mit eigenständigen Kantonen oder die mehrfach diskutierte persönliche oder territoriale Autonomie nichttschechischer Volksgruppen. Auch der Vorschlag, die deutsche Volksgruppe zur zweiten Staatsnation zu machen, scheiterte.

Die wachsende Enttäuschung machte sich eine Sammlungsbewegung zunutze, die am 1. Oktober 1933 unter Führung des Turnlehrers Konrad Henlein (1898-1945) gegründet wurde. Die Sudetendeutsche Heimatfront strebte eine „Zusammenfassung aller Deutschen“ und die Umwandlung der Tschechoslowakei in einen Nationalitätenstaat an. Den tschechoslowakischen Staat und den „Grundgedanken der Demokratie“ erkannte sie aber grundsätzlich an. Eine Anlehnung an das Deutsche Reich, in dem die Nationalsozialisten die Macht übernommen hatten, war anfangs nicht angestrebt, auch sprach Henlein nicht vom Nationalsozialismus, sondern von einer „christlichen und deutschen Weltanschauung“. Kurz vor den Parlamentswahlen 1935 musste sich die Heimatfront auf Druck der tschechoslowakischen Regierung in Sudetendeutsche Partei (SdP) umbenennen. Bei den Wahlen vereinte die noch junge Partei 68 Prozent der sudetendeutschen Wählerstimmen auf sich. Landesweit gewann sie die meisten Stimmen, doch war sie aufgrund des Wahlsystems mit 44 von 300 Mandaten nur die zweitstärkste Partei im Abgeordnetenhaus in Prag.

Die politische Idee eines einigen „Sudetendeutschtums" war ebenso eine nationalistische Idee wie der „Tschechoslowakismus“, weil es ein Volk oder einen Stamm der „Sudetendeutschen“ gar nicht gab. Die deutsche Bevölkerung in Böhmen, Mähren und Schlesien lebte in unterschiedlichen Landschaften, die kein zusammenhängendes und geschlossenes Gebiet bildeten, sie sprachen unterschiedliche deutsche Dialekte und hatten im Alltag schon aufgrund der räumlichen Entfernung wenig miteinander zu tun. Außerdem bildeten die Deutschen keine ethnisch abgeschlossene Gruppe. Welcher Sprache man sich zuwandte, war im 19. und 20. Jahrhundert vielfach Veränderungen unterworfen gewesen. So gab es Böhmen mit tschechischem Familiennamen, die unzweifelhaft tschechischer Abstammung waren, sich aber für die Zugehörigkeit zur deutschen Nation entschieden hatten, während ethnische Deutsche durch Assimilation die tschechische Sprache angenommen hatten.

Angezogen durch die außenpolitischen Erfolge Hitlers richtete sich die Sudetendeutsche Partei ab 1935 stärker auf das Deutschen Reich und den Nationalsozialismus aus, von dem man sich eine „Erlösung“ erhoffte. Am 19. November 1937 wandte sich Henlein erstmals an Hitler und bat ihn, die Sudetendeutschen zu unterstützen. Dabei schlug er den „Anschluß des gesamten böhmisch-mährischen Raums an das Reich“ vor. Hitler legte am 5. November 1937 vor den Spitzen der Wehrmacht und des Auswärtigen Amtes dar, dass er die Besetzung Österreichs und der Tschechoslowakei plante. Die Sudetendeutsche Partei diente seinen Interessen, konnte er sie doch zur Destabilisierung der Tschechoslowakei einsetzen. Hitler wies Henlein an, der tschechoslowakischen Regierung Forderungen zu stellen, die diese unmöglich annehmen könne. Indes sprach Henlein in der Öffentlichkeit weiterhin von einer Autonomie für seine Volksgruppe. Am 24. April 1938 verkündete der Parteiführer in Karlsbad acht Forderungen an die tschechoslowakische Regierung. Henlein verlangte die volle Gleichberechtigung der deutschen Minderheit als Volksgruppe, die Anerkennung eines deutschen Siedlungsgebiets innerhalb der Tschechoslowakei, den Aufbau einer deutschen Selbstverwaltung mit ausschließlich deutschen Beamten, die Wiedergutmachung der ab 1918 erlittenen wirtschaftlichen Schäden der deutschsprachigen Bewohner und endlich die ,volle Freiheit des Bekenntnisses zum deutschen Volkstum und zur deutschen Weltanschauung“, womit die Ideolo- 


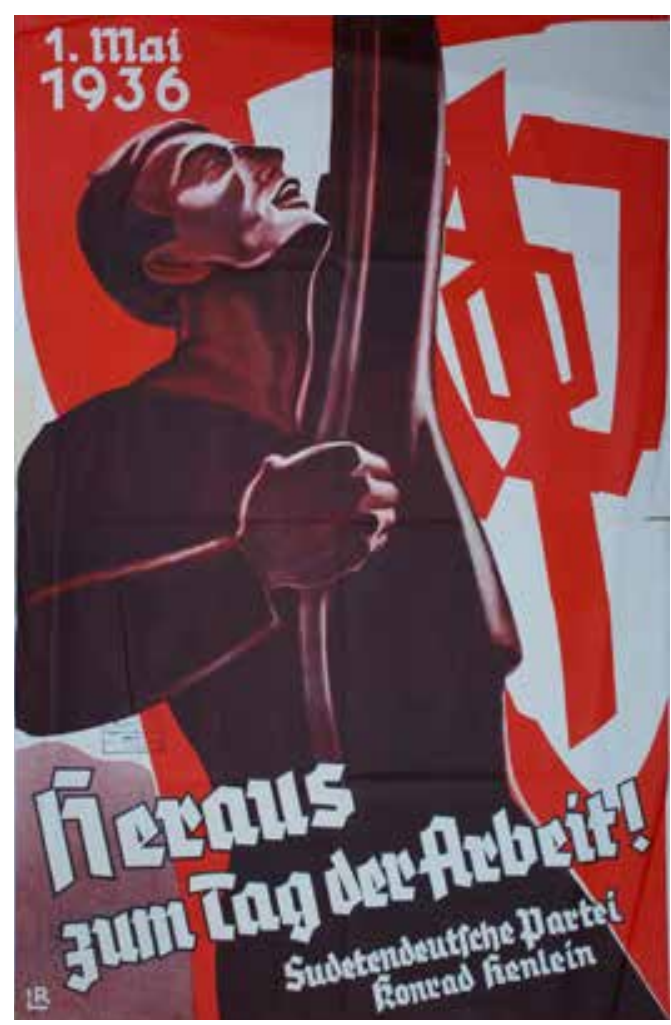

gie des Nationalsozialismus gemeint war. Präsident Edvard Beneš lehnte diese Forderungen ab. Am 30. Mai 1938 erklärte Hitler dem Oberkommando der Wehrmacht, dass es sein unabänderlicher Beschluss sei, die Tschechoslowakei durch eine militärische Aktion zu zerschlagen und er nur noch auf einen geeigneten Anlass warte. Zuvor, im März 1938, war Österreich mit dem Deutschen Reich vereinigt worden.

Die Sudetendeutsche Partei erhielt enormen Zulauf. Ihre Mitgliederzahl stieg von 548.338 am 31. Dezember 1937 auf 1,35 Millionen im Oktober 1938. Damit war sie eine Massenpartei geworden. In Ritschka (Adlergebirge) traten 926 der 929 Einwohner der Bewegung bei. Der Bund der Landwirte und die Christlich-Soziale Volkspartei verließen die tschechoslowakische Regierung, der sie über viele Jahre angehört hatten, und traten am 22./23. März 1928 zur Sudetendeutschen Partei über. Das bedeutete das Ende des „Aktivismus“, der aktiven Mitarbeit im tschechoslowakischen Staat.

Das Selbstbewusstsein der „nationalen“ Deutschen äußerte sich in Demonstrationen, Kundgebungen und bewussten Störungen tschechoslowakischer Einrichtungen. Wiederholt kam es zu Schlägereien zwischen sudetendeutschen Aktivisten, tschechischen Polizisten und Befürwortern des tschechoslowakischen Staats. So heizte sich die Stimmung im Frühjahr und Sommer 1938 enorm auf. Die Sudetenkrise, wie dieser Konflikt bezeichnet wird, half Hitler, seine Stellung gegenüber den anderen europäischen Mäch-

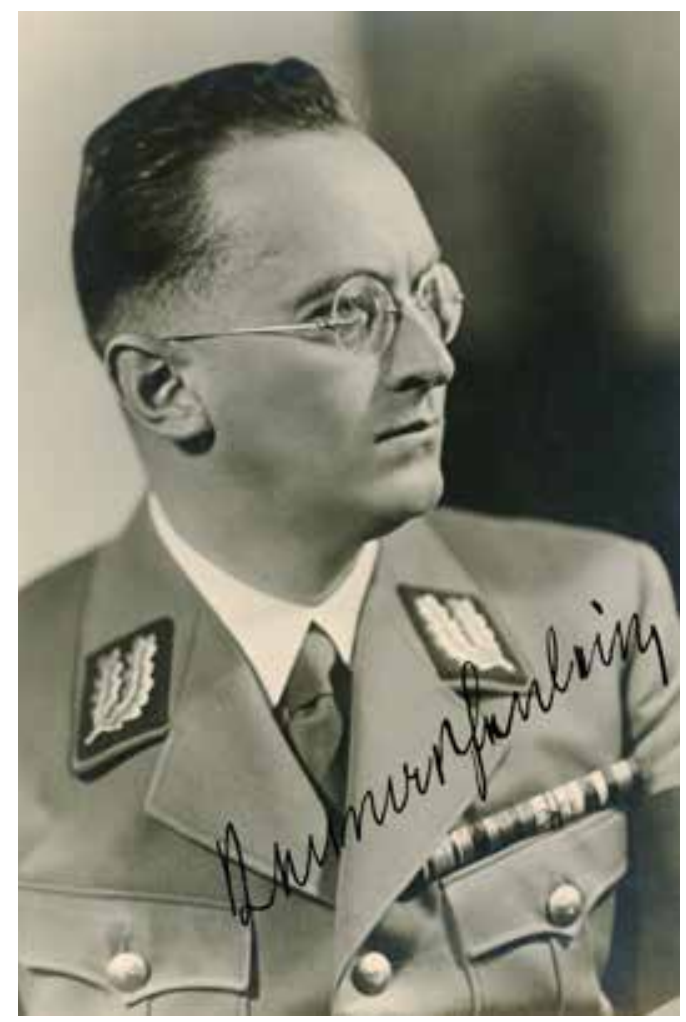

„Heraus zum Tag der Arbeit", Plakat der Sudetendeutschen Partei, 1936

๑) Muzeum města Ústí nad Labem

Konrad Henlein, Führer der Sudetendeutschen Partei, später Gauleiter und Reichsstatthalter im Reichsgau Sudetenland, Aufnahme um 1939

๑ Krajská vědecká knihovna v Liberci ten zu stärken, weshalb er ihn über die Sudetendeutsche Partei anfachte und steuerte.

Im Mai 1938 schien ein Kriegsausbruch bevorzustehen. Beunruhigt durch militärische Bewegungen nahe der Grenze beschloss die tschechoslowakische Regierung am 20. Mai 1938 eine teilweise Mobilmachung. 199.000 Mann wurden zur Armee einberufen. Die Entscheidung löste hektische Verhandlungen zwischen den Siegermächten des Ersten Weltkriegs und der tschechoslowakischen Regierung aus. Um einen Krieg zu verhindern, stimmten Frankreich und Großbritannien einer Verhandlungslösung zu. Der britische Gesandte Lord Walter Runciman (1870-1949) versuchte, ab 3. August 1938 zwischen den Sudetendeutschen und der Regierung zu vermitteln. Er gab die Empfehlung, Grenzbezirke mit „bedeutender deutscher Bevölkerungsmehrheit" unverzüglich an Deutschland anzugliedern und für weitere Gebiete Volksabstimmungen anzusetzen. Dadurch bestärkt, forderte die Sudetendeutsche Partei unter der Losung „Heim ins Reich“ die Ausgliederung der deutschsprachigen Gebiete aus der Tschechoslowakei.

Angestachelt durch Hitler, der in scharfen Tönen gegen die Tschechoslowakei wetterte, begannen gewaltbereite Mitglieder der Sudetendeutschen Partei am 13. September einen Aufstand. Sie überfielen tschechische „Grenzler“, besetzten Behörden und misshandelten Juden, Kommunisten und Sozialdemokraten. Zugleich flüchteten Sudetendeutsche über die Grenze auf Reichsgebiet, wo mit dem Sudetendeutschen Freikorps eine Bürgerkriegsarmee aufgestellt wurde, die Angriffe auf 
„Im Bedarfsfalle werden wir alle Soldaten", Herbst 1938. Mit dem Plakat, das in einer tschechischen und in einer deutschen Fassung im ganzen Land verteilt wurde, riefen die tschechoslowakischen Behörden zur Verteidigung des Staates auf. Damit bereitete man die Bevölkerung auf einen drohenden Angriff der Wehrmacht vor. ๑ Muzeum města Ústi nad Labem tschechische Zollämter verübte und tschechische Beamte über die Grenze verschleppte. Die Aufständischen konnten mehrere Grenzstreifen im Westen und Norden Böhmens unter ihre Kontrolle bringen, doch gelang es der Tschechoslowakischen Armee, ihnen wieder mehrere Gebiete zu entreißen.

Unterdessen bemühten sich die europäischen Mächte, die unter allen Umständen einen Krieg vermeiden wollten, um eine Beilegung des Konflikts. Nach einem Gespräch Hitlers mit dem britischen Premierminister Neville Chamberlain (1869-1940) stimmten Großbritannien und Frankreich einer Abtretung von Gebieten mit über 50 Prozent deutscher Bevölkerung an Deutschland $\mathrm{zu}$, was die tschechoslowakische Regierung am 21. September 1938 akzeptierte. Die Einzelheiten dieser Abtretung wurden auf der Münchner Konferenz am 29./30. September 1938 ohne Beteiligung der Tschechoslowakei verhandelt. Gemäß dem Münchner Abkommen besetzten Einheiten der Wehrmacht zwischen dem 1. und dem 10. Oktober 1938 die mehrheitlich deutsch besiedelten Grenzgebiete. Dadurch verlor die Tschechoslowakei 14 Prozent ihres

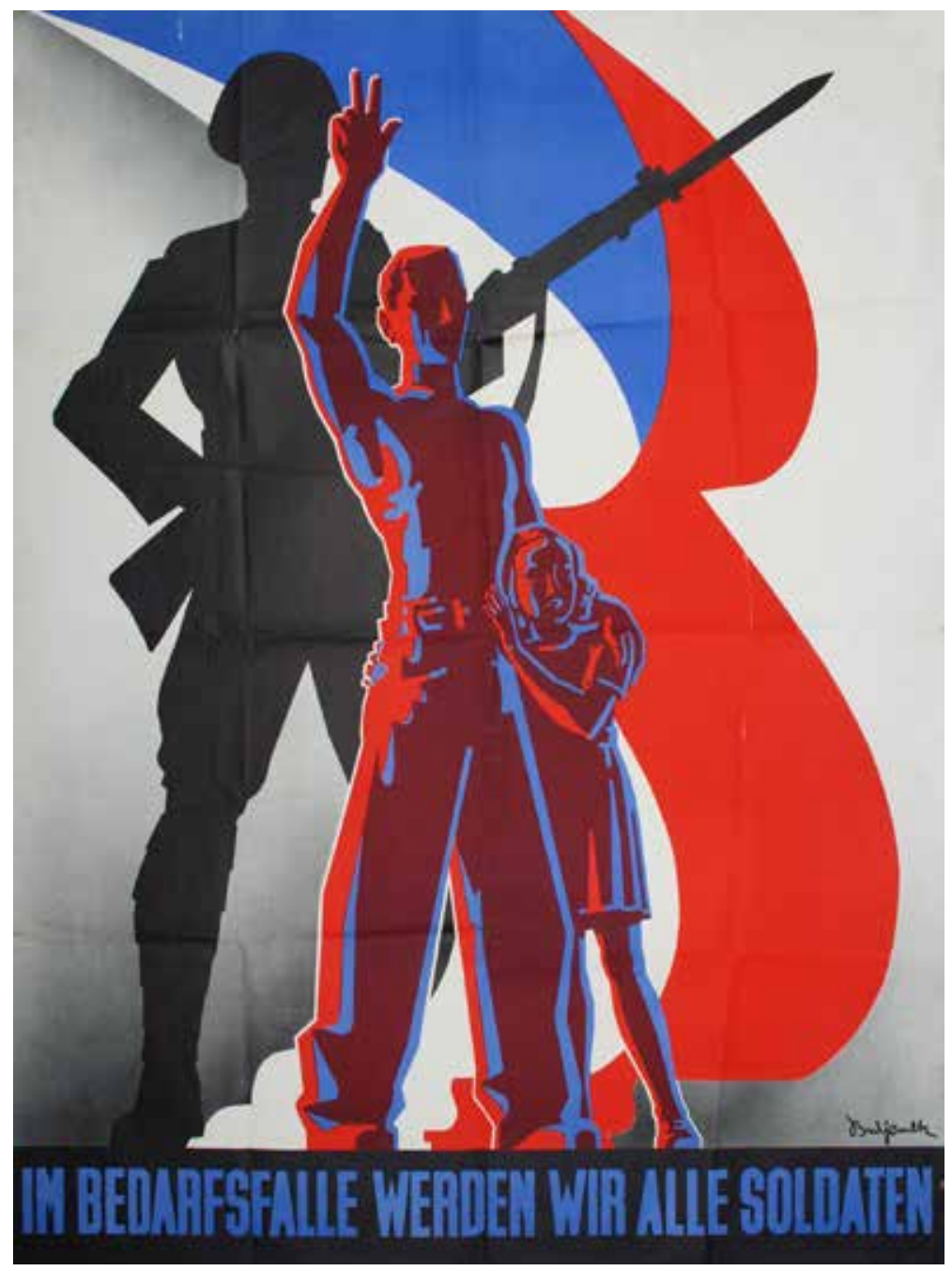

Staatsgebiets an das Deutsche Reich. Hitler, der eigentlich die gesamte Tschechoslowakei zerschlagen wollte, musste sich vorerst mit diesem Anteil zufrieden geben. Er hielt sich aber nicht an die im Münchner Abkommen zugesagte Garantie für das Fortbestehen einer verkleinerten Tschechoslowakei. Bereits im März 1939 ließ er die „Rest-Tschechei“ besetzen und als Protektorat Böhmen und Mähren dem Reich angliedern.

\section{Der Reichsgau Sudetenland}

Die deutschsprachige Bevölkerung begrüßte mehrheitlich den Anschluss an das Deutsche Reich. Die über die Grenzen zu Sachsen und Bayern einrückende Wehrmacht wurde mit Jubel empfangen. Adolf Hitler und Konrad Henlein feierte man als „Befreier des Sudetenlandes“. Nicht erfreut waren Sozialdemokraten, Kommunisten und andere Gegner des Nationalsozialismus, die sich auf Verfolgungen einstellen mussten. Bis zuletzt hatten die Arbeiterparteien versucht, eine Herauslösung der deutschsprachigen Gebiete aus der Tschechoslowakei und eine Machtübernahme der Nationalsozialisten zu verhindern. Nur vordergründig brachte die Angliederung an das Deutsche Reich eine „Befreiung“. Tatsächlich führte sie dazu, dass sich die Sudetendeutschen der nationalsozialistischen Diktatur unterwerfen mussten. Die deutsche Bevölkerung erhielt nicht die gewünschte Selbstverwaltung, sondern musste sich in ein totalitäres Regime einfügen.

Die Bestimmungen des Münchner Abkommens führten zu einer Ausreise der tschechischen Beamten und Militärangehörigen sowie aller tschechischen Familien, die nach 1918 in die deutsch besiedelten Gebiete gekommen waren. Außerdem flohen viele, die eine Verfolgung befürchten mussten, etwa Juden und erklärte Gegner des NSStaates, in das verbliebene tschechoslowakische Gebiet. Darüber, wie viele Menschen vertrieben wurden oder geflohen sind, liegen keine sicheren Zahlen vor. Schätzungen gehen davon aus, dass rund 160.000 Menschen das Gebiet verließen, darunter Einwohner tschechischer und jüdischer Abstammung, Sozialdemokraten, Kommunisten sowie reichsdeutsche und österreichische Emigranten, die in der Tschechoslowakei Zuflucht gesucht hatten. Durch die Besetzung des Protektorates Böhmen und Mähren im März 1939 wurden diese Flüchtlinge von den Nationalsozialisten eingeholt. Mindestens 20.000 sudetendeutsche Regimegegner wurden verhaftet. Etwa 5.000 Menschen gelang die Ausreise ins Exil, vor allem nach Großbritannien.

Bei dem abgetretenen Gebiet mit deutscher Mehrheit handelte es sich um geografisch zersplitterte Randregionen Böhmens, Mährens und 
Schlesiens. Dieses Gebiet hatte niemals untereinander eine Einheit gebildet, sondern war immer mit dem böhmischen Binnenland verbunden gewesen, von dem es nun durch die neue Reichsgrenze getrennt war. Der genaue Verlauf der Grenze wurde am 20. November 1938 festgelegt. Er richtete sich danach, ob die Ortschaften bei der Volkszählung 1910 eine deutsche oder eine tschechische Mehrheit gehabt hatten. Die Grenzziehung führte nicht zu einer vollständigen ethnischen Trennung, denn in den Landesteilen, die an das Deutsche Reich fielen, lebten über 400.000 Tschechen, während im verkleinerten Staatsgebiet der Tschechoslowakei noch 240.000 Deutsche wohnten. Die größte Stadt mit deutscher Bevölkerung, Ostrau (Ostrava), war bei der Tschechoslowakei geblieben, desgleichen die deutschen „Sprachinseln“ um Brünn (Brno) und Iglau (Ihlava).

Dem „Gesetz über die Wiedervereinigung der sudetendeutschen Gebiete“ vom 21. November 1938, das die Eingliederung ins Reichsgebiet verfügte, folgte das „Gesetz über die Gliederung der sudetendeutsche Gebiete“ vom 25. März 1939, mit dem eine territoriale Neugliederung vorgenommen wurde. Während die Landesteile im Südosten und Süden Böhmens und Mährens dem Regierungsbezirk Niederbayern-Oberpfalz des Freistaats Bayern sowie den Reichsgauen Niederdonau und Oberdonau (ehemals Nieder- und Oberösterreich) angegliedert wurden, bildete man aus den deutsch besiedelten Randgebieten in Nordböhmen und Nordmähren den „Reichsgau Sudetenland“ - ein disparates, aus zwei voneinander getrennten Gebietsteilen bestehendes, nunmehr abrupt vom mehrheitlich tschechischen Kernland separiertes Gebilde. Aufgrund der starken Ausrichtung des wirtschaftlichen und kulturellen Lebens auf Prag war es ohne ein gewachsenes Zentrum. Mehr als Verlegenheitslösung wurde Reichenberg, die größte Stadt dieses Gebiets, mit dem „Gesetz über den Aufbau der Verwaltung im Reichsgau Sudetenland“ vom 15. April 1939 zur „Gauhauptstadt“ erklärt.

Nach der Volkszählung vom 17. Mai 1939 lebten im Reichsgau Sudetenland auf 22.587 Quadratkilometer insgesamt 2.945.261 Einwohner. Darunter befanden sich etwa 400.000 Tschechen (13 Prozent), die keinerlei Minderheitsrechte genossen. Das tschechische Vereinsleben wurde aufgelöst und tschechische Schulen geschlossen. Bewohner tschechischer Sprache, die bereits 1910 in dem Gebiet gelebt hatten, konnten sich für die Annahme der deutschen Staatsbürgerschaft entscheiden. Etwa 60 Prozent taten das auch, um in der Heimat verbleiben zu können. Eine Minderheit optierte für die Staatsangehörigkeit der Tschechoslowakei. Ob- wohl eine Aussiedlung dieses Bevölkerungsteils vorgesehen war, unterblieb diese. Ein Grund war, dass die „Rest-Tschechei“ seit 1939 als Protektorat Böhmen und Mähren ebenfalls unter deutscher Herrschaft stand und ohnehin eine „Germanisierung“ des Sudetenlands wie auch der Protektoratsbevölkerung vorgesehen war. Etwa 40.000 bis 45.000 Einwohner galten nach nationalsozialistischer Definition als „Nichtarier“. Sie waren unmittelbar nach dem „Anschluss“ des Sudetenlandes der radikalen Vernichtungspolitik der Nationalsozialisten ausgeliefert. Nur ein kleiner Teil der jüdischen Bevölkerung überlebte.

Der Reichsgau Sudetenland war als „Mustergau“ organisiert und mit einem Verwaltungsaufbau versehen, der bei einer Neugliederung des Reichsgebiets als Vorbild dienen sollte. Die staatliche Verwaltung und die Parteigliederung waren deckungsgleich. Konrad Henlein war sowohl Reichsstatthalter und damit der Leiter der „Gauselbstverwaltung“ als auch Gauleiter der NSDAP, der einzig zugelassenen Partei. Der „Führer der Sudetendeutschen“ genoss hohes Ansehen und besaß eine relativ starke Machtposition. Die gesamte Verwaltung wurde nach Vorbildern aus dem Reich umorganisiert. So richtete man nach preußischem Vorbild drei Regierungsbezirke mit Verwaltungssitzen in Karlsbad, Aussig und Troppau ein, die sich aus Landkreisen zusammensetzten.

Der Angliederung an das Deutsche Reich folgte eine nationalsozialistische Durchdringung der gesamten Gesellschaft. Es vollzog sich eine „Gleichschaltung im Zeitraffer“. Innerhalb weniger Monate wurde das nachvollzogen, was im Reichsgebiet in den fünf Jahren seit der nationalsozialistischen Machtergreifung geschehen war. Ein „Stillhaltekommissar für Organisationen“ löste Verbände und Vereine auf, die nicht in den NS-Staat passten. Nur Organisationen, die sich nationalsozialistischen Gliederungen unterstellten, durften bestehen bleiben. Das führte zu einer weitgehenden Beseitigung des traditionellen Vereinswesens. Am 15. September 1940 bestanden nur noch 15.000 von ehemals 81.000 Vereinen. Auch die Sudetendeutsche Partei musste sich auflösen. Da führende Nationalsozialisten ihr misstrauten und sie für unzuverlässig hielten, erfolgte keine automatische Übernahme der Mitglieder in die NSDAP, was viele „Volkstumskämpfer“ enttäuschte. Im Zuge der „Gleichschaltung“ wurden zahlreiche Verwaltungspositionen mit „Altreichsdeutschen“ besetzt, die nicht aus dem Sudetenland stammten. Bei der einheimischen Bevölkerung provozierte diese Entwicklung ein Gefühl der „Fremdherrschaft“. Dem gilt freilich entgegen- nächste Seite:

Übersichtskarte vom Gau

Sudetenlands und von der Tschecho-Slowakei, März 1939. Die Karte zeigt den Reichsgau Sudetenland mit seiner Gliederung in drei Regierungsbezirke Eger (Verwaltungssitz in Karlsbad), Aussig und Troppau sowie die anderen an das Deutsche Reich angegliederten Gebiete.

๑ Bayerisches Hauptstaatsarchiv München, Sudetendeutsches Archiv 


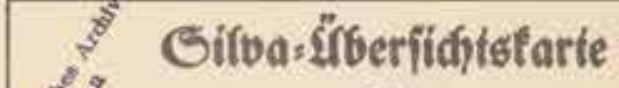

Sau Subetentano

unb bon Der Tídpedjo. Slowatei

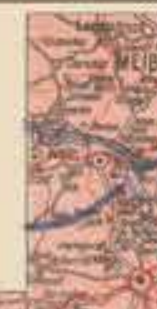

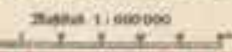

(3)

yth

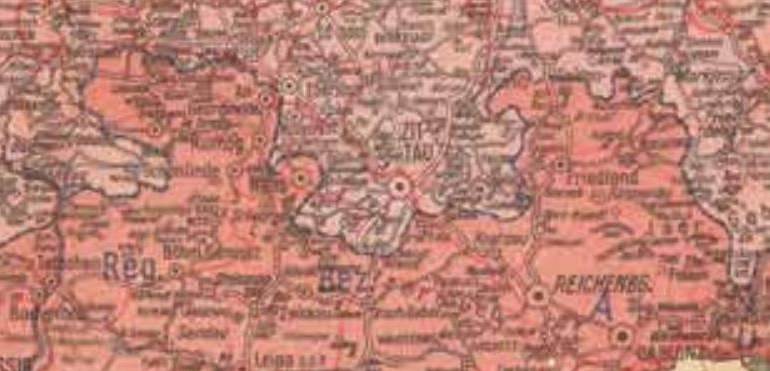

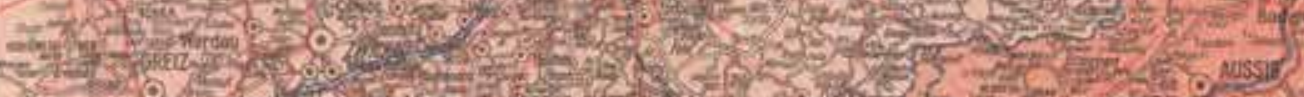

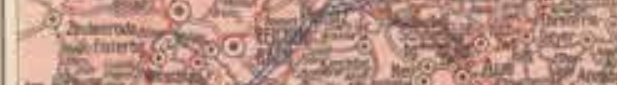

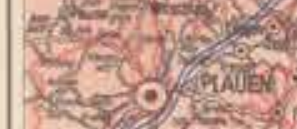

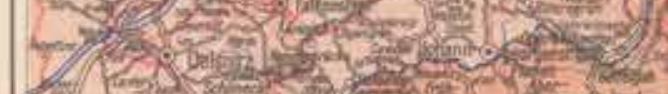

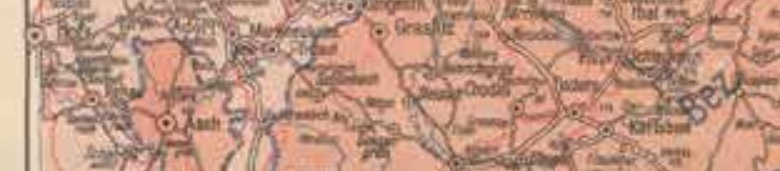

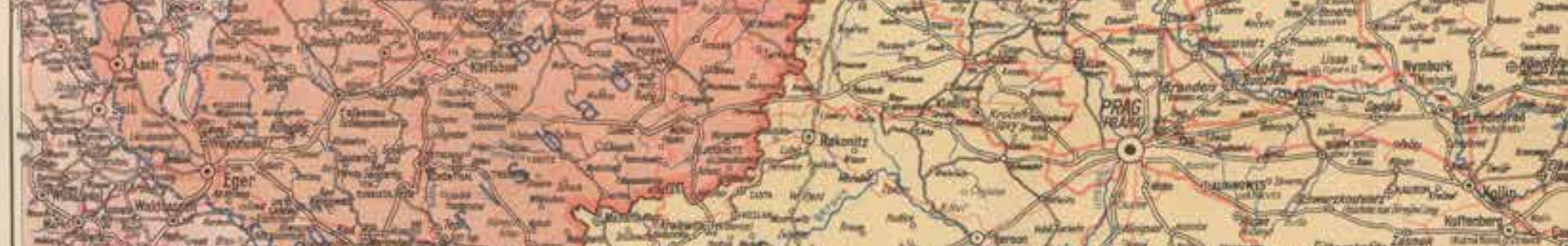

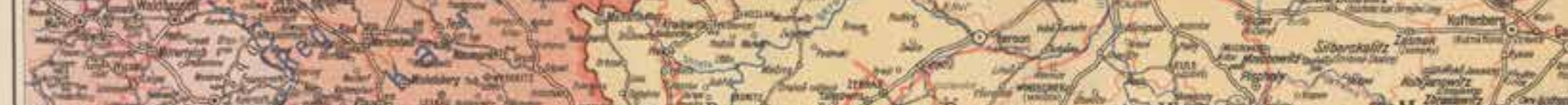

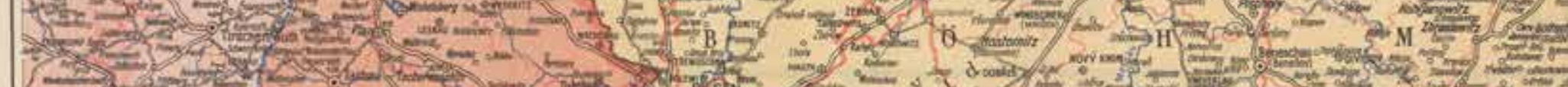

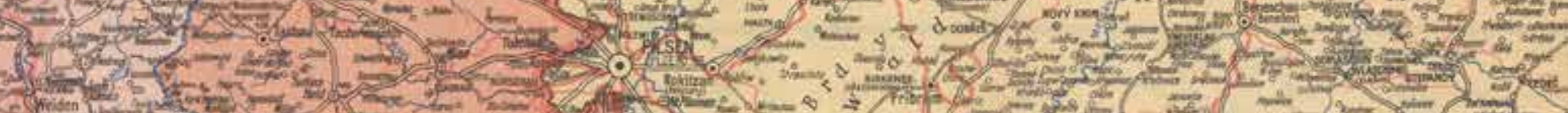

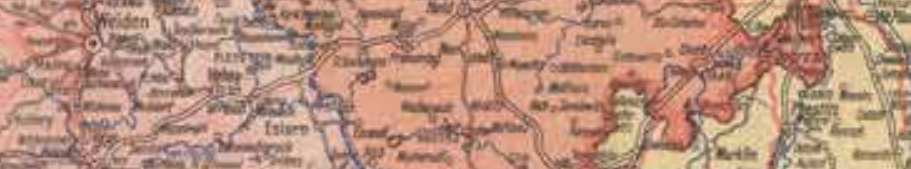

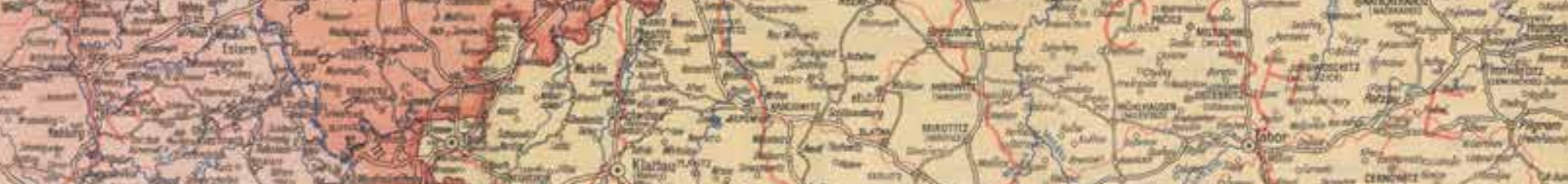

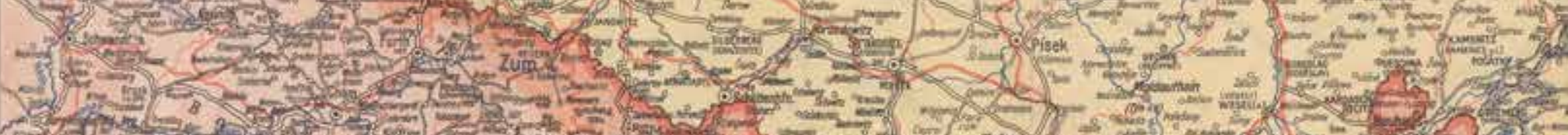

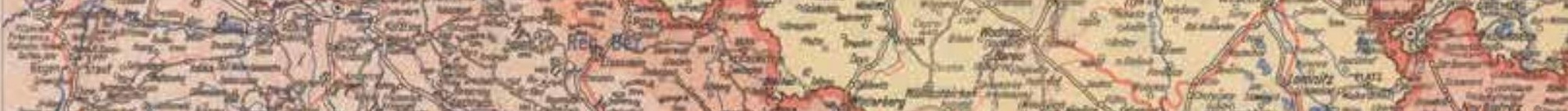

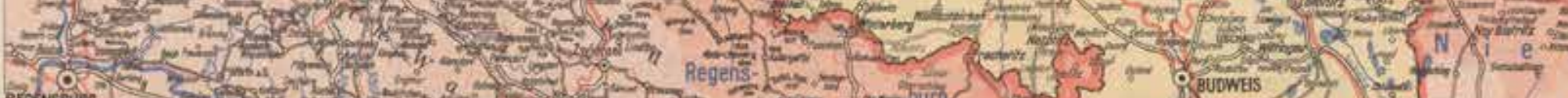
Risonsioving

$=$ Netwerse

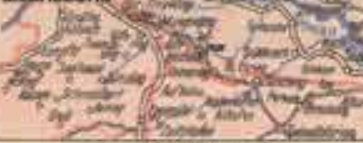

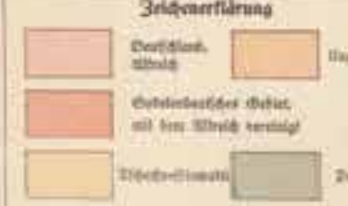

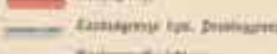

meren

notumenting

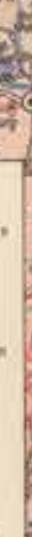

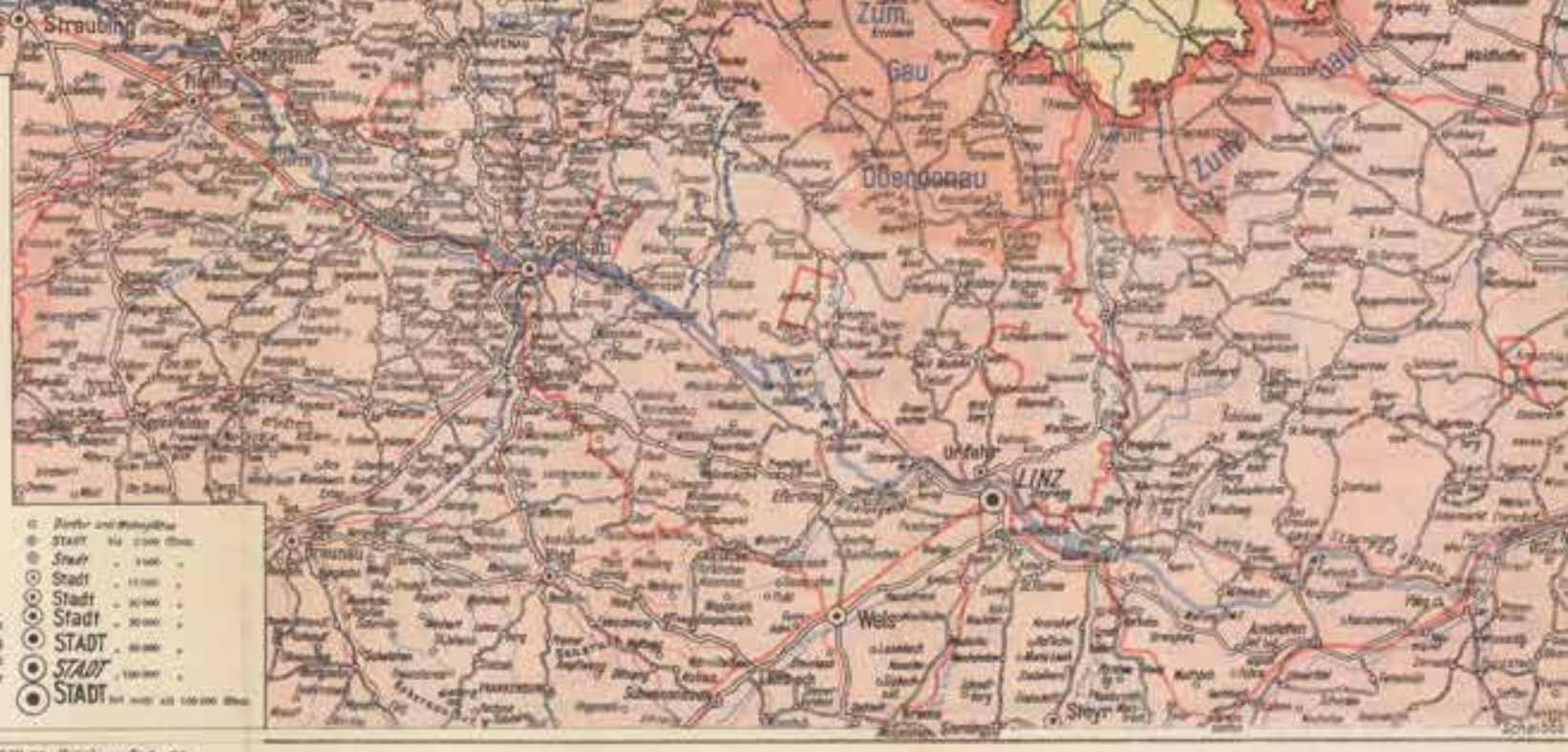




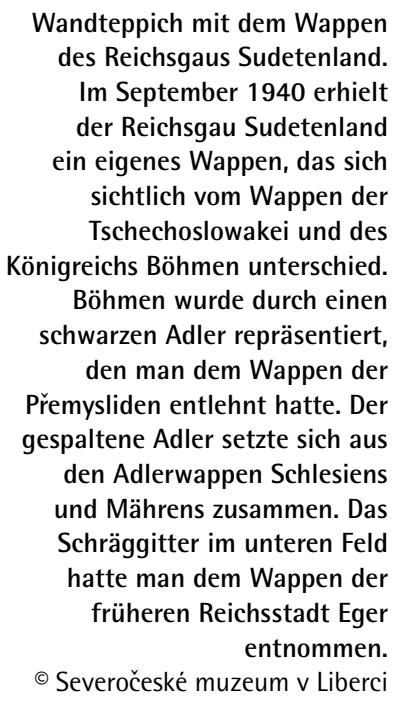

Fibel aus dem Reichsgau Sudetenland, gedruckt 1941 in Reichenberg

๑ Muzeum města Ústi nad Labem

Zum Weiterlesen (mit sämtlichen Nachweisen):

Matthias Donath/Lars-Arne Dannenberg (Hrsg.): Böhmen ist mein Heimatland! Deutsche und Tschechen in Nordböhmen 1918-1945. Země česká, domov můj! Němci a češi v severnich Čechách 1918-1945. Begleitbuch zur Ausstellung vom 27.10.2018 bis 31.3.2019 in Weesenstein, erscheint im Oktober 2018

Autoren

Dr. Lars-Arne Dannenberg, Dr. Matthias Donath Herausgeber der „Sächsischen Heimatblätter“
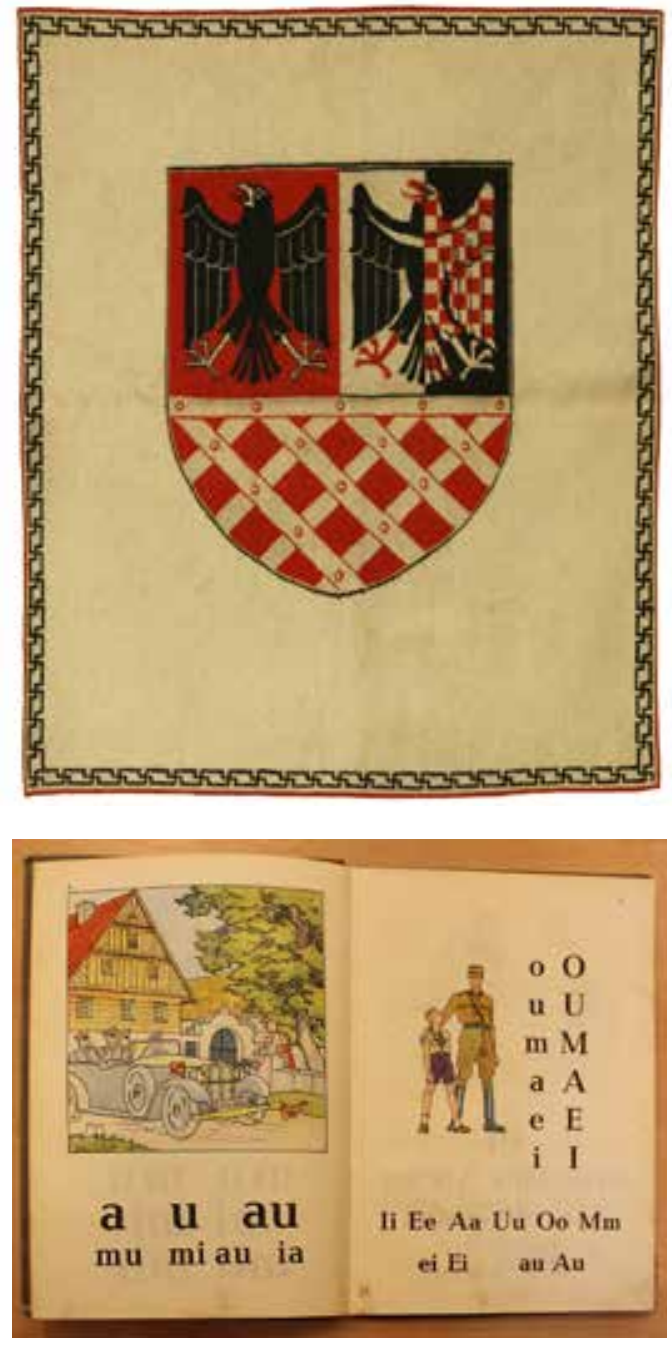

zuhalten, dass die höheren Verwaltungspositionen fast ausschließlich mit Sudetendeutschen besetzt waren.

Die anfängliche Euphorie der Sudetendeutschen schlug schon nach wenigen Monaten in Missstimmung und Resignation um. Denn die Eingliederung in das Deutsche Reich brachte zahlreiche Nachteile. Die Einführung der reichsdeutschen Normen in Recht, Verwaltung und Wirtschaft beseitigte vieles, was zur deutschböhmischen Identität gehört hatte. Das Eigenständige, das Henlein eigentlich hatte bewahren wollen, ging verloren. Hinzu kam, dass sich die wirtschaftliche Lage verschlechterte. Die Textilund Konsumgüterindustrie wurde durch die Einbeziehung in das Zoll- und Wirtschaftsgebiet des Deutschen Reichs von den internationalen Rohstoff- und Absatzmärkten abgeschnitten. Einige Betriebe versuchten, die Zollbestimmungen zu umgehen, indem sie für einige Wochen weiter unter dem Markenzeichen „Made in Czechoslovakia“ produzierten und ihre Waren über die Tschechoslowakei ausführten. Generell waren die reichsdeutschen Wirtschaftsinteressen für das Sudetenland eher von Nachteil. So verfügte die nordböhmische Textilindustrie über eine veraltete Maschinenausstattung und über enorme Produktionskapazitäten, die im deutschen Binnenmarkt nicht benötigt wurden. Das Gablonzer Schmuck- und Glasgewerbe war vom Export abhängig, waren doch 95 Prozent der Produkte ins Ausland geliefert worden. Diese Kunden brachen weg. Um die Arbeitskräfte für die Rüstungsindustrie einsetzen zu können, forderte die SS 1939, die „Mumpitzindustrie“ zu schließen. Durch Umstrukturierungen fielen zahlreiche Arbeitsplätze, weshalb rund 170.000 Arbeitskräfte in das „Altreich“ abwanderten. Dort lockten außerdem höhere Löhne. Beim Umtausch der Kronen in Reichsmark hatte die Reichsbank einen für die Sudetendeutschen ungünstigen Umtauschkurs durchgesetzt. So verloren Arbeiter bei der Währungsumstellung einen Teil ihres Reallohns. Die Lebenshaltungskosten hingegen hatten sich seit Oktober 1938 erhöht. Insgesamt sank der Lebensstandard der sudetendeutschen Bevölkerung.

Die erhoffte friedliche Entwicklung des Reichsgaus Sudetenland blieb aus, denn bereits ein Jahr nach der Angliederung dieses Gebiets begann der Zweite Weltkrieg. Auch aus dem Sudetenland wurden junge Männer zum Kriegsdienst eingezogen. Der Anteil gefallener Sudetendeutscher war enorm. Rund 175.000 Sudetendeutsche, etwa sechs Prozent der Vorkriegsbevölkerung, fielen im Zweiten Weltkrieg. Das war deutlich mehr als in anderen Teilen des Reichs.

Der Reichsgau Sudetenland blieb bis Kriegsende von Kriegshandlungen weitgehend verschont. Weil das nordböhmische Gebiet lange außerhalb der Reichweite der alliierten Flugzeuge lag, galt es als „Reichsluftschutzkeller“. 1944 gab es erstmals Luftangriffe. Diese richteten sich vor allem gegen kriegswichtige Industriebetriebe, die bewusst im Sudetengau angesiedelt worden waren. Der größte von ihnen war das Hydrierwerk in Maltheuern (Záluží) bei Brüx (Most), wo aus Braunkohle Benzin gewonnen wurde.

Am Ende des Zweiten Weltkriegs, am 8. und 9. Mai 1945, wurde das Sudetenland von amerikanischen und sowjetischen Truppen weitgehend kampflos besetzt. Damit endete die nationalsozialistische Herrschaft. Auch der Reichsgau Sudetenland und alle reichsdeutschen Einrichtungen hörten zu bestehen auf. Die Tschechoslowakische Republik entstand erneut und erhielt ihre Staatsgrenzen zurück, die sie vor dem Münchner Abkommen gehabt hatte. Rund 3 1/2 Millionen Deutsche mussten den wiedergegründeten Staat verlassen. Es war das Ende des Zusammenlebens von Deutschen und Tschechen in Böhmen. 